\title{
OVERVIEW OF PATIENT PREFERENCES IN THE SURGICAL MANAGEMENT PLAN OF EARLY BREAST CANCERS
}

\author{
Ayesha Khan, Afroz Mushtaq, Syeda Rifaat Qamar Naqvi, Razia Bano, Fahad Ali Khan*, Ruqia Begum**, Said Zaman, Sana Mushtaq** \\ Combined Military Hospital/National University of Medical Sciences (NUMS) Rawalpindi Pakistan, *Pakistan Institute of Medical Sciences, Islamabad Pakistan, \\ **Bahria International Hospital, Islamabad Pakistan, ${ }^{* * * K h y b e r ~ C o l l e g e ~ o f ~ D e n t i s t r y, ~ P e s h a w a r ~ P a k i s t a n ~}$
}

\section{ABSTRACT}

Objective: To determine patient preferences in the surgical options of early breast cancers and surgeon's role in the decisionmaking.

Study Design: Cross-sectional study.

Place and Duration of Study: Breast Surgery Department, Combined Military Hospital, Rawalpindi Pakistan, from Nov 2020 to May 2021.

Methodology: Patients having early carcinoma breast were studied, i.e., clinical stage 1 or 2, and their surgical preference was recorded. The cases were discussed in multidisciplinary meetings, and a discussion session with patient conducted and then final decision taken from the patient was recorded again, and the results compared.

Results: A total of 28 patients were included in this study and their surgical preferences recorded. Of these patients $22(78.5 \%)$ agreed to breast conservation initially, whereas one of the patients wanted mastectomy. Five $(17.8 \%)$ patients were undecided between the two. After multidisciplinary team recommendation and discussion with surgeon, only one patient opted for mastectomy $(3.6 \%)$.

Conclusion: Patients with early breast cancer when offered a surgical decision between breast conservation and mastectomy mostly opt for breast conservation; those who select mastectomy do so because of the fear of recurrence.

Keywords: Breast cancer, Breast conservation surgery, Joint decision making, Mastectomy, Patient preference.

How to Cite This Article: Khan A, Mushtaq A, Naqvi SRQ, Bano R, Khan FA, Begum R, Zaman S, Mushtaq S. Overview of Patient Preferences in the Surgical Management Plan of Early Breast Cancers. Pak Armed Forces Med J 2021; 71(6): 1947-1949. Doi: https://doi.org/10.51253/pafmj.v6i6.7267

This is an Open Access article distributed under the terms of the Creative Commons Attribution License (https://creativecommons.org/licenses/by-nc/4.0/), which permits unrestricted use, distribution, and reproduction in any medium, provided the original work is properly cited.

\section{INTRODUCTION}

Breast cancer is the most common cancer in women, making up about $25.2 \%$ of cancers in total, and $14.7 \%$ of deaths due to cancer in females worldwide. ${ }^{1}$ The main modality of breast cancer management rests on surgical resection of the tumor either by mastectomy, or breast-conserving surgery (BCS; lumpectomy), combined with systemic therapies and radiation. Mastectomy was previously the gold standard treatment, but now increasing popularity of BCS has changed all guidelines especially for early breast cancer. Preservation of the breast without decreasing survival, and patient well being led to the popularity of BCS. ${ }^{2}$ Ever since BCS has made its way into the standard of care, there has been speculation of the perspective of patient regarding the surgical decision between mastectomy and BCS. A number of factors determine the decision between these two different modes of surgery.

Some studies report that bigger tumor size, lymph nodes involvement, ${ }^{3}$ higher stage and higher

Correspondence: Dr Syeda Rifaat Qamar Naqvi, Associate Professor of Surgery, Combined Military Hospital Rawalpindi Pakistan

Received: 19 Aug 2021; revision received: 24 Nov 2021; accepted: 26 Nov 2021 histologic grade lead to a preference of mastectomy. The use of chemotherapy preoperatively and the surgical qualification of surgeon (breast surgeon, oncologic surgeon or general surgeon) are suggested to be factors that lead to a preference of BCS by another study. ${ }^{4}$ In this study, we explore initial, and final patient preferences in regard to BCS and mastectomy in early breast cancer.

\section{METHODOLOGY}

This cross-sectional study was conducted at a dedicated Breast Clinic in Combined Military Hospital, Rawalpindi, from Nov 2020 to May 2021. Sampling technique was non-probability sampling. Early breast carcinoma (EBC) cases were studied, i.e. those having clinical stage 1 or 2 .

Inclusion Criteria: Patients included in the study were those with histopathological diagnosis of carcinoma breast, no prior history of cancer, aged 30-80 years, who are scheduled to undergo mastectomy or BCS as breast cancer treatment for EBC, ie stages 1 and 2 of breast cancer.

Exclusion Criteria: Patients who had larger tumour size or T4 tumors, metastatic disease, connective tissue 
disorders and those not candidates for BCS were not included in the study.

Their work up was done, and the cases discussed one multidisciplinary meetings. Those in whom both breast conserving surgery and mastectomy were considered as oncologically safe options, these patients were then called to know their preference. The cases were discussed in multidisciplinary meetings, and a discussion session with patient conducted. Then final decision taken from the patient.

Patient histories were taken; demographic factors were noted. The decision prior to discussion in multidisciplinary meetings was noted, and then the decision rediscussed with the patient after MDT recommendation and a detailed session with the surgeon.

IRB approval was obtained. All women gave oral and written informed consent, showing that they were aware of the investigational nature of the study. All data was entered in SPSS version 25, and described in the form of numbers and frequencies, and age describes as mean and standard deviation. The results were tabulated.

\section{RESULTS}

Surgical preferences of a total of 28 patients were studied. Of these patients $22(78.5 \%)$ agreed to breast conservation initially, whereas one of the patients wanted mastectomy. Five (17.8\%) patients were undecided between the two. After MDT recommendation and discussion with surgeon, only one patient opted for mastectomy $(3.6 \%)$. The major factor responsible for her preference for mastectomy was found to be the fear of recurrence after conservative surgery as they had heard about a close acquaintance who had a negative outcome after breast cancer diagnosis (Table-I).

\begin{tabular}{l|c}
\multicolumn{2}{|c}{ Table-I: Initial patient preferences regarding type of surgery. } \\
\hline Initial patient preferences & $\mathbf{n ~ ( \% )}$ \\
\hline Preferring breast conservation surgery & $24(85.7 \%)$ \\
\hline Undecided on type of surgery & $4(14.3 \%)$ \\
\hline
\end{tabular}

Fifteen patients had right sided disease (53.6\%), 12 had left sided cancer (42.9\%) and one had bilateral disease (3.6\%). Stage wise 8 patients presented with T1 disease $(28.6 \%)$ and 20 patients had T2 (71.4\%). Nodal stage wise, 23 patients were N0 $(82.1 \%)$, and 5 patients had N1, (17.9\%).

The rest of 27 patients agreed to and underwent BCS. Eight of these patients undergoing BCS underwent ALND (28.6\%). The rest of 20 patients undergoing BCS and one undergoing mastectomy all has SLNB done $(71.4 \%)$, all of which were negative. 10 patients underwent upfront surgery $(35.7 \%)$. While 12 were given neoadjuvant systemic therapy first and then proceeded to surgery $(42.8 \%)$ as shown in Table-II.

Table-II: Final choice of surgery.

\begin{tabular}{l|c}
\hline Final choice of surgery & $\mathbf{n ~ ( \% )}$ \\
\hline Underwent breast conservation surgery & $27(96.4 \%)$ \\
\hline Underwent Mastectomy & $1(3.6 \%)$ \\
\hline
\end{tabular}

\section{DISCUSSION}

Radical mastectomy, initially put in practice by William Halsted in 1894, and proved to be a good modality of local disease control, but the knowledge of its curative use limited. ${ }^{5}$ The preservation of breast without decreasing overall and disease free survival was the beginning of the era of BCS2. Many prospective randomized trials, ${ }^{5-8}$ showed that mastectomy had no survival over BCS. BCS has a similar outcome from oncologic point of view, while reducing the psychological negative impact, superior cosmesis, and lesser complications. . $^{5-8}$

The four stages of patient selection for BCS are: A clinical history and examination, radiology, histology, and assessment of the patient's needs and expectations. ${ }^{9}$

The choice of BCS in selected cases remains an oncologically safe one. BCS followed by radiotherapy in early breast cancer has been shown to have a similar outcome in terms of local and distant recurrence, and overall survival in comparison with mastectomy. ${ }^{10,11}$

If leaving residual breast tissue behind puts the patient at an increased risk of local recurrence, then BCS is not advisable. These include: Multicentricity with foci far from each other, showing diffuse pleomorphic microcalcifications on mammogram, persistent positive resection margin, previous history of radiotherapy to the breast or chest wall, and pregnancy (radiotherapy is a contraindication) BCS remains an option in third trimester, so breast radiotherapy can be started postpartum. ${ }^{12}$

Relative contraindications are connective tissue disorders, notably scleroderma and systemic lupus erythromatosis (SLE), ${ }^{13,14}$ and a big tumor in a small breast. Figure shows the factors that result in the ultimate choice of surgery between mastectomy and BCS in early breast cancer.

In regard to the choice of surgery between BCS and mastectomy, studies have shown that this decision-making is complicated, with factors in play such 
as anxiety related to cancer recurrence, hearing about failed BCS treatments, concerned about follow-up imaging, or family history of breast cancer. ${ }^{15}$

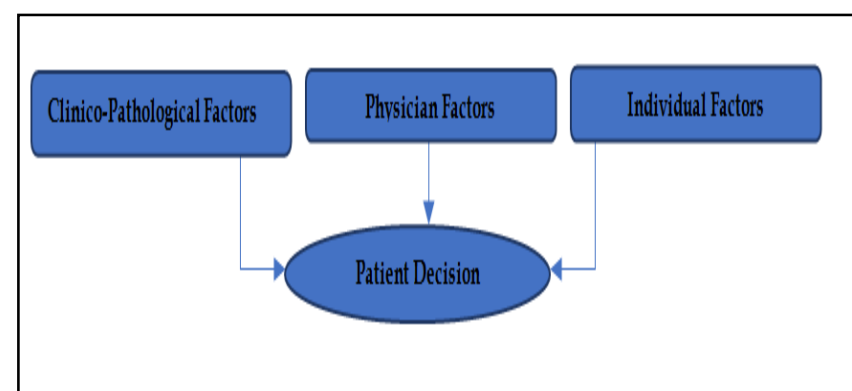

Figure: Factors that result in the ultimate choice of surgery between mastectomy and BCS in early breast cancer.

The deciding of surgical modality and its interactive process between the doctor and patient is complicated, and difficult to interpret. More and more are aimed towards the process, to ascertain what factors influence the process. Studies done on these individual preferences found that women tend to choose mastectomy because it offers more reassurance to the patient. ${ }^{16}$

The other significant factor in opting BCS is the doctor's recommendation, comparable survival, and a lesser aggressive approach surgically involved. A study by Mastaglia et al. in which patients rate factors that influenced their deciding process, physician recommendation was an important one among them. ${ }^{17,18}$ Our study showed, that after a discussion between patient and doctor, patients were more inclined towards conservation surgery than mastectomy.

\section{CONCLUSION}

Patients with EBC, when offered a choice between breast conservation and mastectomy mostly favour BCS, those who prefer mastectomy mostly do so because of the fear of recurrence. Although offering BCS expertise at breast cancer centers shows the quality of their care, the concurrent discussions and counseling regarding BCS are important. This information aids in deciding for or against BCS. Patients should be counselled and their queries addressed to help in the decision making if they are eligible for BCS.

\section{Conflict of Interest: None.}

\section{Authors' Contribution}

AK: Manuscript writing, FM: Data analysis, SRQN: Iiterature Search, RB: Data Collection, FAK: Manuscript writing, RB: Iiterature Search, SZ: Proof Reading, SM: Proof Reading.

\section{REFERENCES}

1. Ferlay J, Soerjomataram I, Dikshit R, Eser S, Mathers C, Rebelo $\mathrm{M}$, et al. Cancer incidence and mortality worldwide: sources, methods and major patterns in GLOBOCAN 2012. Int J Cancer 2015; 136(5): E359-86.
2. Hoover S, Bloom E, Patel S. Review of breast conservation therapy: then and now. ISRN Oncol 2011; 2011(1): 617593.

3. Zhang B, Song Q, Zhang B, Tang Z, Xie X, Yang H, et al. A 10year (1999-2008) retrospective multi-center study of breast cancer surgical management in various geographic areas of China. Breast 2013; 22(5): 676-681.

4. Klemens AE, Olsen-Deeter L, Hsu CH, Bouton ME, Djenic B, Winton LM, et al. Factors which affect the use of lumpectomy and mastectomy in an underinsured, safety net hospital population. Am J Surg 2015; 209(6): 985-991.

5. van Maaren MC, de Munck L, de Bock GH, Jobsen JJ, van Dalen $\mathrm{T}$, Linn SC, et al. 10 year survival after breast-conserving surgery plus radiotherapy compared with mastectomy in early breast cancer in the Netherlands: A population-based study. Lancet Oncol 2016; 17(8): 1158-1170.

6. Corradini S, Bauerfeind I, Belka C, Braun M, Combs SE, Eckel R, et al. Trends in use and outcome of postoperative radiotherapy following mastectomy: a population-based study. Radiother Oncol 2017; 122(1): 2-10.

7. Shaverdian N, Wang X, Hegde JV, Aledia C, Weidhaas JB. The patient's perspective on breast radiotherapy: Initial fears and expectations versus reality. Cancer 2018; 124(8): 1673-1681.

8. Morrow M, Strom EA, Basstt LW, Derahaw DD, Fowble B. Standard for breast conservation therapy in the management of invasive breast carcinoma. CA Cacer J Clin 2002; 52(5): 277-300.

9. Kim K, Park HJ, Shin KH, Kim JH, Choi DH, Park W, et al. Breast Conservation Therapy Versus Mastectomy in Patients with T12N1 Triple-Negative Breast Cancer: Pooled Analysis of KROG 14-18 and 14-23. Cancer Res Treat 2018; 50(4): 1316-1323.

10. Wang J, Wang S, Tang Y, Jing H, Sun G, Jin J, et al. Comparison of treatment outcomes with breast-conserving surgery plus radiotherapy versus mastectomy for patients with stage $i$ breast cancer: a propensity score-matched analysis. Clin Breast Cancer 2018; 18(5): e975-e984.

11. Katz SJ, Lantz PM, Janz NK, Fagerlin A, Schwartz K, Liu L, et al. Patient involvement in surgery treatment decisions for breast cancer. J Clin Oncol 2005; 23(24): 5526-5533.

12. Gu J, Groot G, Boden C, Busch A, Holtslander L, Lim H. Review of factors influencing women's choice of mastectomy versus breast conserving therapy in early stage breast cancer: a systematic review. Clin Breast Cancer 2018; 18(4): 539-554.

13. Lee WQ, Tan VKM, Choo HMC, Ong J, Krishnapriya R, Khong S. Factors influencing patient decision-making between simple mastectomy and surgical alternatives. BJS Open 2018; 3(1): 31-37.

14. Gu J, Groot G, Holtslander L, Engler-Stringer R. Understanding women's choice of mastectomy versus breast conserving therapy in early-stage breast cancer. Clin Med Insights Oncol 2017; 11(1): 1179554917691266.

15. Mastaglia B, Kristjanson LJ. Factors influencing women's decisions for choice of surgery for Stage I and Stage II breast cancer in Western Australia. J Adv Nurs 2001; 35(6): 836-847.

16. Paluch-Shimon S, Pagani O, Partridge AH, Abulkhair O, Cardoso MJ, Dent RA, et al. ESO-ESMO 3rd international consensus guidelines for breast cancer in young women (BCY3). Breast 2017; 35(1): 203-217.

17. Hershman DL, Buono D, Jacobson JS, McBride RB, Tsai WY, Joseph KA, et al. Surgeon characteristics and use of breast conservation surgery in women with early stage breast cancer. Ann Surg 2009; 249(5): 828-833.

18. Temple WJ, Russell ML, Parsons LL. Conservation surgery for breast cancer as the preferred choice: a prospective analysis. J Clin Oncol 2006; 24(2): 3367-3373. 